Short Paper

\title{
Releases of Trichopria drosophilae on cherry, in three locations at different altitudes in South Tyrol (north-eastern Italy) and its potential to parasitise Drosophila suzukii
}

Freisetzungen von Trichopria drosophilae an Kirsche in drei Anlagen in verschiedenen Höhenlagen in Südtirol und Parasitierungspotenzial gegenüber Drosophila suzukii

Rilasci di Trichopria drosophilae su ciliego in tre località a diverse altitudini in Alto Adige e potenziale di parassitizzazione nei confronti di Drosophila suzukii

Martina Falagiarda ${ }^{1}$, Silvia Schmidt ${ }^{1}$

${ }^{1}$ Laimburg Research Centre

\section{ABSTRACT}

In recent years, Drosophila suzukii Matsumura (Diptera: drosophilidae) caused serious damages in cherries and small fruits cultivations in South Tyrol, making it difficult for growers to continue their activities without production losses. Biological control of the pest could play an important role in its population regulation, by lowering the pest pressure at the beginning of the season. This study aims to evaluate the potential of Trichopria drosophilae Perkins (Hymenoptera: Diapriidae), an indigenous pupal parasitoid of drosophilids, in parasitizing $D$. suzukii in cherry orchards situated at different altitudes and characterized by different agronomic peculiarities. The release trials showed the ability of the parasitoid to find and parasitise artificially exposed pupae of $D$. suzukii in two out of three localities, up to $915 \mathrm{~m}$. The results highlight the importance for the released species of an adequate surrounding environment for its spread and establishment.

\section{KEYWORDS}

Spotted-wing drosophila, parasitism, Diapriidae, biological control

\section{CITE ARTICLE AS}

Falagiarda Martina, Schmidt Silvia, (2020). Releases of Trichopria drosophilae on cherry, in three locations at different altitudes in South Tyrol (northeastern Italy) and its potential to parasitize Drosophila suzukii.

Laimburg Journal 02/2020 DOI: $10.23796 / \mathrm{LJ} / 2020.006$

CORRESPONDING AUTHOR

Martina Falagiarda

Laimburg 6, Pfatten, I-39040 Auer (BZ), Italy

martina.falagiarda@laimburg.it 0471969630 


\section{INTRODUCTION}

Drosophila suzukii (Matsumura) is a polyphagous pest native to South East Asia that invaded Europe, North and South Americas [1] [2] and was first detected in Italy in 2009 [3]. It infests several fruit crops, including stone fruits and berries, causing important economic damage in many European regions [4] [5]

In recent years, numerous strategies have been evaluated to be used against this pest in order to develop an integrated and effective management of the species. Containment practices are mainly based on the application of chemical insecticides and on cultural control, such as the use of insect exclusion nets [6] and sanitation methods. Nevertheless, its management remains difficult due to the enormous reproductive potential and dispersal capability of the species. Other methods are being investigated for $D$. suzukii control on a larger temporal scale, which include biological control [6] [7] [8] [9]. The study of the biology of $D$. suzukii's natural enemies is of fundamental importance to understand how to favour their activity as antagonists in order to obtain a long-term population regulation through augmentative biological control methods. In the invaded areas, studies were conducted on the presence and efficacy of local parasitoid species, which could be selected as biocontrol agents [7] [9] [10] [11] [12] [13] [14] [15]. The larval parasitoids Asobara tabida (Hymenoptera: Braconidae), Leptopilina heterotoma, and L. boulardi (both Hymenoptera: Figitidae) rarely complete their development on $D$. suzukii due to its high immune response [7] [15]. Only two pupal parasitoids, Trichopria drosophilae (Hymenoptera: Diapriidae) and Pachycrepoideus vindemmiae (Hymenoptera: Pteromalidae), could successfully develop on $D$. suzukii [11] [13]. Several laboratory studies [14] [16] [17] have identified in T. drosophilae a possible candidate for the control of $D$. suzukii populations, due to its good parasitism rate, a high longevity, and the ability to effectively attack the pupae in a temperature range of $15-35^{\circ} \mathrm{C}$ [17]. Field studies [18] [19] showed a reduction in $D$. suzukii emergence in $T$. drosophilae-treated areas and a lower fruit infestation in both commercial cherry orchards and unmanaged areas surrounding the orchards. However, augmentative releases performed at altitudes higher than $700 \mathrm{~m}$ showed a reduced performance of parasitoids [18].
In South Tyrol, cherry production covers 95 ha [20] and most cherry orchards are located between 800 and $1300 \mathrm{~m}$ a.s.l. [21]. Furthermore, many small fruits, such as strawberries and raspberries, are located at higher altitudes, between 500 and $1800 \mathrm{~m}$ a.s.I. [22]. Usually, levels of parasitism tend to decrease with increasing altitude, probably due to the cooler temperatures at higher elevations [23]. Nevertheless, some braconid and pteromalid hymenopterans, including $P$. vindemmiae, have been found to attack their hosts at elevations up to 1600 $\mathrm{m}$, while the diapriid endoparasitoid Coptera haywardi could parasitise Anastrepha fraterculus and A. obliqua (Diptera: Tephritidae) up to $1200 \mathrm{~m}$ [24].

The aim of this study is to provide new insights into T. drosophilae's ability to find and successfully parasitise $D$. suzukii pupae in field conditions at different altitudes. For this purpose, four parasitoid releases were performed between May and June 2018 in three different sites, all characterised by the presence of a cherry orchard and a hedgerow. The persistence of $T$. drosophilae was evaluated up to 4 weeks after the last release. Climatic conditions such as temperature and humidity were also considered in the study, to investigate their influence on parasitism levels.

\section{METHODS}

\section{STUDY SITE AND MICROCLIMATIC CONDITIONS}

Three cherry orchards, located at different altitudes in the province of South Tyrol, were selected for the release trials. These are located close to the Laimburg Research Centre (site 1), at $220 \mathrm{~m}$ a.s.I., in Lengstein (site 2), at 915 m a.s.l., and in Kastelruth (site 3), at $1115 \mathrm{~m}$ a.s.I.. In all sites, a hedgerow consisting of different plant species, including ornamental trees and shrubs, was present along one side of the orchard. Cherry orchards were managed by integrated pest management, except in site 1 , where no insecticides were applied. In site 1 , the hedgerow separates the orchard from a building, while in site 3 apple orchards are located behind the hedge. In site 2, the hedge is thicker than in the other sites and divides the cultivated land from meadows. Moreover, insect exclusion nets ( $1.5 \times 1 \mathrm{~mm}$ mesh) were installed in this site, around the orchard, which separated the hedge from the cherry trees. Site descriptions are reported in Table 1.

In each site, one datalogger was positioned along the hedge to measure temperature and relative humidity. The dataloggers were hung in shady areas to avoid the exposition to direct sun, which could lead to incorrect measurements.

\section{SENTINEL TRAPS}

Sentinel traps (modified after Rossi Stacconi et al. 2017 [17]) were built to verify the presence of natural population of parasitoids and to evaluate the presence and persistence of released parasitoids. Two small plastic cups ( $h=35 \mathrm{~mm}, \mathrm{~d}=70 \mathrm{~mm}$ ) were put inside red delta traps. Strawberries and bananas slices were placed inside each cup, respectively, and $D$. suzukii third stadium larvae were added, which were close to pupation. Cups were closed by a fine mesh $(0.8 \mathrm{~mm})$ net to stop $D$. suzukii adults and other drosophilids and to allow the parasitoids entrance. Cups were changed weekly and, after field exposure, pupae were kept in the laboratory, in a climatic chamber at $\mathrm{T}=21 \pm 2{ }^{\circ} \mathrm{C}, \mathrm{RH}=75 \%$ and $16: 8$ hours L:D, until eclosion.

\section{PRESENCE OF NATURAL POPULA- TIONS OF PARASITOIDS}

Before starting the release trials, sentinel traps were placed in the hedgerow along the cherry orchard to verify the presence of natural populations of already established parasitoids. Starting from April 9, six weeks before the first release, a red delta trap was placed in the hedgerow of the cherry orchard in site 1 . The presence of natural populations of parasitoids was evaluated with the same procedure in sites 2 and 3 starting respectively 4 and 2 weeks before the first release of $T$. drosophilae.

\section{RELEASE TRIAL}

T. drosophilae individuals for the trial were provided by Bioplanet s.r.l. (Cesena, Italy), in plastic bottles containing 500 individuals each, either in adult form or inside parasitised $D$. melanogaster pupae. The parasitoids were released one day after arrival of the bottles in all three sites. A total of 4 releases of $1000 \mathrm{~T}$. drosophilae individuals each were carried out on May 24 and 31 and on June 14 and 21. Prior to the first release, a check was carried out on 100 individuals of $T$. drosophilae received, to verify the 
proportion between males and females inside the bottle.

Three sentinel traps were placed along the hedge and in the cherry orchard, respectively $15 \mathrm{~m}$ from the release point (Fig. 1). Two traps were hung along the hedge at about $1.5 \mathrm{~m}$ height and one inside the orchard, on a cherry tree branch. Below each Delta trap, dug in the ground, was placed a jar containing earth and third-stage $D$. suzukii larvae. This was also closed by a thin mesh net $(0.8 \mathrm{~mm})$ to allow the parasitoids entrance and to stop drosophilids.

The traps were changed weekly and brought to the laboratory from May 24 to July 19. After June 28 , only the plastic cups containing strawberry pieces were exposed in the traps. Pupae were collected from the plastic cups and placed in small plastic pots, closed with a modified cap to allow air circulation. Pots were incubated at $21 \pm 1{ }^{\circ} \mathrm{C}, 75 \% \mathrm{RH}$ and 16:8 L:D until eclosion of D. suzukii or parasitoid adults.

\section{AUGMENTORIUM}

A big bucket was used as augmentorium and placed near the release points on May 24. Augmentoria structures are used to confine adult flies while allowing parasitoids to escape through a fine-mesh net [25]. This method is used to facilitate reproduction of released parasitoids and to increase their persistence [26]. The augmentorium contained several fruits infested with $D$. suzukii larvae and adults, to allow parasitoids to multiply inside it. The bucket was closed by a fine-mesh net that only allowed parasitoids entrance and exit. At the end of the trial, it was removed and taken to the laboratory, where the parasitised pupae were counted. The type of exit hole of the pupae indicates whether they have been parasitised or not. Parasitoids emerge from the pupae by chewing a round hole in the puparium, which can be easily recognised under a stereo microscope.

\section{STATISTICAL ANALYSIS}

For sites 1 and 2, a factorial ANOVA was conducted to compare the main effects of substrate (earth/banana/strawberry), trap position (cherry tree/hedgerow South/hedgerow North) and week and the interaction effect of substrate and trap position on parasitisation by $T$. drosophilae. The influence of substrate, trap position and week on overall parasitisation (T. drosophilae and $P$. vindemmiae) in site 1 was also analysed using a factorial ANOVA. The analyses were conducted on the data collected between May 24 and June 28. All data were cube-root transformed to meet the assumptions of normality. Statistical analyses were run using IBM ${ }^{\circledR}$ SPSS $^{\circledR}$ Statistics V24 (IBM Corp., Armonk, NY, USA).

\section{RESULTS}

\section{MICROCLIMATIC CONDITIONS}

In site 1 , the mean temperature ranged between $18.5^{\circ} \mathrm{C}$ and $25.9{ }^{\circ} \mathrm{C}$ during the release trial. A maximum temperature of $35^{\circ} \mathrm{C}$ was reached on June 19 and the minimum temperature $9.4^{\circ} \mathrm{C}$ on June 23 (Tab. 2). Temperatures in sites 2 and 3 are about $4{ }^{\circ} \mathrm{C}$ and $5{ }^{\circ} \mathrm{C}$ cooler compared to site 1 , respectively, and showed similar trends during the trial period (Tab. 2).

Mean relative humidity ranged between $40 \%$ and $90 \%$ and similar maximum and $\mathrm{mi}-$ nimum values were registered in all sites during the trial.

\section{PRESENCE OF NATURAL POPULA- TIONS OF PARASITOIDS}

Only in site 1 was the natural presence of parasitoids observed in the hedgerow before the release trial (Tab. 3). In the last week of April, 6 individuals of the generalist pupal parasitoid $P$. vindemmiae emerged from 6 out of 20 pupae collected from the trap. Larval parasitoids of the genus Leptopilina were recovered from $5 \mathrm{D}$. suzukii pupae exposed in the trap during the second week of May (Tab. 3). No parasitoids were found in the traps exposed in the hedgerows of the cherry orchards before the release trial in sites 2 and 3.

\section{RELEASE TRIAL}

Out of 100 individuals collected from the bottles sent by Bioplanet s.r.l., 48 were males and 52 females.

A total of 687 D. suzukii pupae were collected from the traps on the ground baited with earth between May 24 and July 19 in the three sites; however no parasitoids emerged from these during the whole trial.

In site 1 , a statistically significant effect of substrates $(F[2,32]=4.24 ; p=0.02)$ and weeks $(F[4,32]=3.91 ; p=0.01)$ was observed on $T$. drosophilae parasitisation during the release trial. In fact, parasitisation on strawberry and banana differed significantly from earth, where no parasitoids emerged. Nevertheless, no difference in parasitisation was registered when comparing the two fruit types. $T$. drosophilae successfully attacked $D$. suzukii in the first three weeks but failed in parasitising the pupae in the last two weeks of trial. Trap position did not reveal any significant effect on the parasitisation by $T$. drosophilae and no significant interaction was observed with the type of substrate.

The overall parasitisation, caused by $T$. drosophilae and other parasitoids, did not show any significant effect due to trap position nor week number. Also in this case, the significant difference between substrates ( $F[2$, 36] $=9.18 ; p=0.001$ ) on $T$. drosophilae parasitisation is due to the lack of parasitised pupae in earth, but was not observed between the two fruit types, banana and strawberry. Mean overall parasitisation was almost double compared to only parasitisation by $T$. drosophilae during the release trial; however, it fell below $6 \%$ in the following three weeks (Tab. 4). In sentinel traps exposed in weeks $27-29$, no $T$. drosophilae eclosions were observed in the three sites (Tab. 4).

In site 2 , statistically significant interactions of substrates $(F[2,32]=6.28 ; p=0.005)$ and trap position $(F[2,32]=3.76 ; p=0.03)$ were registered on $T$. drosophilae parasitisation. In fact, parasitoids emergence was observed only once in the sentinel trap positioned on the cherry branch, whereas parasitisation levels were higher in traps exposed on the hedgerow (Fig. 2). Week number did not show any significant interaction with $T$. drosophilae parasitisation, which occurred from week 22 until week 26 (Fig. 2).

No parasitisation of $D$. suzukii pupae was observed in site 3 following the four parasitoids releases.

$P$. vindemmiae emerged from pupae collected in weeks 28 and 29 in all three sites (Tab. 4). In site 1, larval parasitoids of the genus Leptopilina also emerged from pupae during the weeks following the releases. Overall parasitisation assessed in the 3 weeks following the release trial ranged between $5 \%$ and $6 \%$, whereas no $T$. drosophilae eclosions were registered after week 26 (Tab. 4).

More than 100 pupae were found in the augmentorium buckets placed in sites 1 and 2 , where $25 \%$ and $15.5 \%$ of pupae had been parasitised, respectively. Of the 50 pupae found in the augmentorium placed in site 3 , 
only $16 \%$ were parasitised. As parasitisation was assessed by observing the empty puparium, parasitoid species could not be identified.

\section{DISCUSSION}

The results obtained in the current study show the ability of $T$. drosophilae to parasitise $D$. suzukii exposed pupae in different field conditions, both in lower and higher elevations, up to $915 \mathrm{~m}$.

The lack of parasitisation by $T$. drosophilae in Kastelruth may be due to several factors, including microclimatic conditions and habitat structure. The close proximity of the hedgerow to conventionally managed apple orchards might negatively influence the activity of parasitoids, which undergo both direct and indirect effects of pesticides such as the reduction of life span, fecundity, and mobility [27] [28] [29]. At the same time, the higher distance from the forest compared to the other two sites might prevent $T$. drosophilae from spreading and establishing itself in the new environment [12] [15].

In site 2, one parasitisation event by $T$. drosophilae was observed in the trap exposed on the cherry tree in week 26 , although the orchard had been laterally closed by exclusion nets in the previous week. Mesh size of the net is $1.5 \times 1 \mathrm{~mm}$ and therefore allows parasitoids entry. Failure to parasitise pupae exposed in the orchard during the first three weeks may be due to applications of insecticides with a repellent activity on parasitoids, such as pyrethroids [27] [30]. Furthermore, spinosyn-based insecticides showed sub-lethal effects on several parasitoid families including the reduction of reproductive capacity, adult longevity, and host-searching capacity [31]. In Lengstein, D. suzukii parasitisation was carried out exclusively by $T$. drosophilae until week 26 , probably due to the lack of competitors during the whole release trial. $P$. vindemmiae, a potential competitor of $T$. drosophilae [16], was first found later in the season in week 29. This might represent an advantage if augmentative releases of $T$. drosophilae were planned before the increase in population of interspecific competitors such as the generalist pupal parasitoid $P$. vindemmiae.

The opposite situation was observed in Laimburg, at the valley floor, where the presence of natural populations of parasitoids, including P. vindemmaie, could have triggered direct interspecific interactions

\section{ZUSAMMENFASSUNG}

In den letzten Jahren hat Drosophila suzukii Matsumura (Diptera: Drosophilidae) in Südtirol schwere Schäden bei Kirsch- und Beerenobstkulturen verursacht, wodurch es den Anbauern schwer gemacht wurde, ihre Aktivitäten ohne Produktionsausfälle fortzusetzen. Die biologische Bekämpfung des Schädlings könnte in Zukunft eine wichtige Rolle bei der Populationsregulierung der Kirschessigfliege spielen, vor allem um zu Beginn der Saison den Befallsdruck zu senken. Diese Studie zielte darauf ab, das Parasitierungspotenzial von Trichopria drosophilae Perkins (Hymenoptera: Diapriidae), einem einheimischen Puppenparasitoid von Drosophiliden, in Kirschanlagen in unterschiedlichen Anbaulagen in verschiedenen Höhenlagen zu untersuchen. Die Freisetzungsversuche haben gezeigt, dass der Parasitoid die angebotenen Puppen des Schädlings in zwei von drei „behandelten" Anlagen finden und parasitieren kann, bis auf $915 \mathrm{~m}$. Die Ergebnisse zeigen, dass die freigesetzte Art eine geeignete Umgebung für ihre Verbreitung und Etablierung braucht.

\section{RIASSUNTO}

Negli ultimi anni, Drosophila suzukii Matsumura (Ditteri: drosophilidae) ha causato gravi danni alle coltivazioni di ciliegie e piccoli frutti in Alto Adige, rendendo difficile per i coltivatori continuare le loro attività senza perdite di produzione. II controllo biologico di questo fitofago potrebbe svolgere un ruolo importante nella regolazione della popolazione, abbassando la pressione delle infestazioni a inizio stagione. Questo studio mira a valutare il potenziale di Trichopria drosophilae Perkins (Imenotteri: Diapriidae), parassitoide pupale indigeno di drosofilidi, nel parassitizzare $D$. suzukii in impianti di ciliegio in diverse realtà agronomiche a diverse altitudini. Le prove di rilascio hanno mostrato la capacità del parassitoide di trovare e parassitizzare le pupe di $D$. suzukii esposte in due dei tre impianti presi in esame, fino a $915 \mathrm{~m}$. I risultati evidenziano l'importanza per la specie rilasciata di un ambiente circostante adeguato alla sua diffusione e insediamento.

[32] [33]. A study by Wang et al. (2016) [16] showed a reduction in parasitisation by both $T$. drosophilae and $P$. vindemmiae when placed simultaneously in contact with $D$. suzukii pupae under laboratory conditions, suggesting a strong interspecific competition. Nevertheless, T. drosophilae parasitised more hosts than its competitor, showing a higher foraging efficacy and faster host handling time [16]. Nevertheless, temperatures often exceeding $30^{\circ} \mathrm{C}$ in site 1 probably prevented $T$. drosophilae development and favoured $P$. vindemmiae activity [34].

Although $T$. drosophilae is particularly rapid and effective in reproduction during the first days of life [17], the presence of parasitised pupae found on week 24 in different traps in both site 1 and 2 indicates that adults were active one week after their last release. Nevertheless, no $T$. drosophilae developed in the three weeks following the trial. In the study performed by Rossi Stacconi et al. (2018) [18], T. drosophilae eclosions were registered up to 20 weeks following the release period, during which 200,000 individuals were released. In our case, only 4,000 individuals were released in each site, the lower amount could explain their failure to settle in the environment. Moreover, it can be presumed that infested cherries left in the field after harvest have attracted the parasitoids more than the sentinel traps.

The absence of parasitisation of pupae on the ground suggests a strong preference of the parasitoids towards the fruits, which is in line with the results by Wang et al. (2016) 
[16], which showed through laboratory tests a significantly higher parasitisation of the pupae present in the fruits compared to those present in the soil. Another study by Lopez et al. (1999) [35] reports the absence of parasitisation in laboratory-reared pupae of different Anastrepha species exposed on the ground alone. However, Anastrepha pupae exposed on the ground in conjunction with uninfested fruits were parasitised by $C$. haywardi [35]. This preference indicates a certain attractiveness of the fruit towards parasitoids.
The released $T$. drosophilae did not use much of the pupae present in the augmentorium to reproduce. The highest percentage of parasitisation was registered in site 1, where natural populations of parasitoids were already present, and the climatic conditions were probably more favourable to the activity of parasitoids.

In conclusion, this trial confirmed the suitability of $T$. drosophilae in using $D$. suzukii pupae to successfully reproduce and the ability to find pupae in artificially infested fruits. The results indicate that larvae pupating within the fruit are more effectively parasitised than those fallen to the ground, inside the earth. It would therefore be useful to understand the reasons and conditions favourable to this trend. Nevertheless, further research is needed to demonstrate to what extent pupae in rotten fruits fallen to the ground can be parasitised by $T$. drosophilae.

T. drosophilae showed parasitic activity at the beginning of the season at higher elevations, with variable success depending much on habitat structure. In our study, temperature ranges in site 2 and 3 show a similar trend and play a negligible role in parasitisation success. Further investigations are necessary to evaluate the effectiveness of $T$. drosophilae in suppressing $D$. suzukii first generation and its persistence in the environment. 


\section{REFERENCES}

[1] Cini A., loriatti C., Anfora G. (2012). A review of the invasion of Drosophila suzukii in Europe and a draft research agenda for integrated pest management. Bulletin of insectology 65 (1), 149-160. Retrieved March 15, 2019, from http://www.bulletinofinsectology.org/pdfarticles/vol65-2012-149160cini.pdf

[2] Asplen M.K., Anfora G., Biondi A. et al. (2015). Invasion biology of spotted wing Drosophila (Drosophila suzukii): a global perspective and future priorities. Journal of Pest Science 88, 469-494, DOI: 10.1007/s10340-0150681-z.

[3] Grassi A., Palmieri L., Giongo L. (2009). Nuovo fitofago per i piccoli frutti in Trentino. TERRA TRENTINA, 55 (10), 19-23.

[4] De Ros G., Conci S., Pantezzi T. et al. (2015). The economic impact of invasive pest Drosophila suzukii on berry production in the Province of Trento, Italy. Journal of Berry Research 5 (2), 89-96, DOI: 10.3233/JBR150092.

[5] Mazzi D., Bravin E., Meraner M. et al. (2017). Economic impact of the introduction and establishment of Drosophila suzukii on sweet cherry production in Switzerland. Insects 8 (1), 18, DOI: 10.3390/insects 8010018.

[6] Haye T., Girod P., Cuthbertson A.G.S. et al. (2016). Current SWD IPM tactics and their practical implementation in fruit crops across different regions around the world. Journal of pest science 89, 643-651, DOI: 10.1007/s10340-016-0737-8.

[7] Chabert S., Allemand R., Poyet M. et al. (2012). Ability of European parasitoids (Hymenoptera) to control a new invasive Asiatic pest, Drosophila suzukii. Biological Control 63 (1), 40-47, DOI: 10.1016/j.biocontrol.2012.05.005.

[8] Woltz J.M., Donahue K.M., Bruck D.J. et al. (2015). Efficacy of commercially available predators, nematodes and fungal entomopathogens for augmentative control of Drosophila suzukii. Journal of applied entomology 139 (10), 759-770, DOI: 10.1111/jen.12200.

[9] Daane K.M., Wang X.G., Biondi A. et al. (2016). First exploration of parasitoids of Drosophila suzukii in South Korea as potential classical biological agents. Journal of pest science 89 (3), 823-835, DOl: 10.1007/s10340-016-0740-0.
[10] Rossi Stacconi M.V., Grassi A., Dalton D.T. et al. (2013). First field records of Pachycrepoideus vindemiae as a parasitoid of Drosophila suzukii in European and Oregon small fruit production areas. Entomologia, 1 (1), 11-16, DOI: 10.4081/entomologia.e3.

[11] Gabarra R., Riudavets J., Rodríguez G.A. et al. (2015). Prospects for the biological control of Drosophila suzukii. BioControl 60 (3), 331-339, DOI: 10.1007/s10526-014-9646-z.

[12] Miller B., Anfora G., Buffington M. et al (2015). Seasonal occurrence of resident parasitoids associated with Drosophila suzukii in two small fruit production regions of Italy and the USA. Bulletin of Insectology 68 (2), 255-263. Retrieved March 15, 2019, from http://www.bulletinofinsectology.org/pdfarticles/vol68-2015-255-263miller.pdf.

[13] Rossi Stacconi M.V., Buffington M., Daane K.M. et al. (2015). Host stage preference, efficacy and fecundity of parasitoids attacking Drosophila suzukii in newly invaded areas. Biological Control 84, 28-35, DOI: 10.1016/j.biocontrol.2015.02.003.

[14] Mazzetto F., Marchetti E., Amiresmaeili N. et al. (2016). Drosophila parasitoids in northern Italy and their potential to attack the exotic pest Drosophila suzukii. Journal of pest science $89,837-850$, DOI: 10.1007/s10340-016-0746-7.

[15] Knoll V., Ellenbroek T., Romeis J. et al. (2017). Seasonal and regional presence of hymenopteran parasitoids of Drosophila in Switzerland and their ability to parasitize the invasive Drosophila suzukii. Scientific reports 7:40697, DOI: 10.1038/srep40697.

[16] Wang X.G., Kaçar G., Biondi A. et al. (2016). Foraging efficiency and outcomes of interactions of two pupal parasitoids attacking the invasive spotted wing drosophila. Biological control 96, 64-71, DOI: 10.1016/j.biocontrol.2016.02.004

[17] Rossi Stacconi M.V., Panel A., Baser N. et al. (2017). Comparative life history traits of indigenous Italian parasitoids of Drosophila suzukii and their effectiveness at different temperatures. Biological control 112, 20-27, DOI: 10.1016/j.biocontrol.2017.06.003.

[18] Rossi Stacconi M.V., Amiresmaeili N., Biondi A. et al. (2018). Host location and dispersal ability of the cosmopolitan parasitoid Trichopria drosophilae released to control the invasive spotted wing Drosophila. Biological control 117, 188-196, DOI: 10.1016/j.biocontrol.2017.11.013.
[19] Rossi Stacconi M.V., Grassi A., loriatti C. et al. (2019). Augmentative releases of Trichopria drosophilae for the suppression of early season Drosophila suzukii populations. BioControl 64, 9-19, DOI: 10.1007/s10526-01809914-0.

[20] Istat - Istituto Nazionale di Statistica (Ed.) (2018). Agricoltura e zootecnia. Tavola C17 Superficie (ettari) e produzione (quintali): melo, pero, albicocca, ciliegio. Dettaglio per Provincia - Anno 2018. Retrieved March 15, 2019, from http://agri.istat.it/jsp/dawinci.jsp?q=plC170000020000053201\&an $=20$ $18 \& i g=1 \& c t=266 \& i d=21 \mathrm{~A}|15 \mathrm{~A}| 30 \mathrm{~A}$.

[21] Vi.P (Ed.) (2018). Sehr gute Kirschenernte. Retrieved March 15, 2019, from https://www.vip.coop/de/business/vi-pgenossenschaften/sch\%C3\%B6ne-vinschgerkirschen/72-2835.html.

[22] IDM (Ed.). Piccoli cuori di gusto. Retrieved March 15, 2019, from https://www.prodottitipicialtoadige.com/it/prodotti/piccoli-frutti/informazioni.html.

[23] Hodkinson I.D. (2005). Terrestrial insects along elevation gradients: species and community responses to altitude. Biological reviews 80 (3), 489-513, 이: $10.1017 /$ S1464793105006767.

[24] Sivinski J., Pinero J., Aluja M. (2000). The distributions of parasitoids (Hymenoptera) of Anastrepha fruit flies (Diptera: Tephritidae) along an altitudinal gradient in Veracruz, Mexico. Biological Control 18 (3), 258-269, DOI: $10.1006 /$ bcon.2000.0836.

[25] Klungness L.M., Jang E.B., Mau R.F. et al. (2005). New sanitation techniques for controlling tephritid fruit flies (Diptera: Tephritidae) in Hawaii. Journal of Applied Sciences and Environmental Management 9 (2), 5-14. Retrieved March 15, 2019 from http://www.bioline.org.br/request?ja05038.

[26] Trottin Y., Paulhiac E., Zicot A. et al. (2014) Experimental studies on Drosophila suzuki in protected strawberry crops: biology of the pest and effectiveness of a parasitoid of pupa in field conditions. In: Fondazione Edmund Mach (Ed.). Proceeding of the IOBC VIII Workshop on Integrated Soft Fruit Production, Vigalzano di Pergine Valsugana (TN) 26-28 May 2014, pp. 26-28.

[27] Desneux N., Decourtye A., Delpuech J. M. (2007). The sublethal effects of pesticides on beneficial arthropods. Annual Review of Entomology 52, 81-106, DOI: 10.1146/annurev.ento.52.110405.091440. 
[28] Cloyd R. (2012). Indirect effects of pesticides on natural enemies. In: Soundararajan R. P. (Ed.). Pesticides. Advances in Chemical and Botanical Pesticides. IntechOpen, London, United Kingdom, pp. 127-150, DOI: $10.5772 / 48649$.

[29] El-Wakeil N., Gaafar N., Sallam A. et al. (2013). Side effects of insecticides on natural enemies and possibility of their integration in plant protection strategies. In: Trdan S. (Ed.). Insecticides. Development of safer and more effective technologies. IntechOpen, London, United Kingdom, pp. 3-56, DOI: 10.5772/54199.
[30] Longley M., Jepson P.C. (1996). Effects of honeydew and insecticide residues on the distribution of foraging aphid parasitoids under glasshouse and field conditions. Entomologia Experimentalis et Applicata 81 (2), 189-198, DOI: 10.1111/j.15707458.1996.tb02031.x.

[31] Williams T., Valle J., Viñuela E. (2003). Is the naturally derived insecticide Spinosad ${ }^{\circledR} \mathrm{com}-$ patible with insect natural enemies? Biocontrol science and technology 13 (5), 459-475, DOI: 10.1080/0958315031000140956.

[32] Hardy I.C.W., Goubault M., Batchelor T.P. (2013). Hymenopteran contests and agonistic. In: Hardy I.C.W., Briffa M. (eds.). Animal contests. Cambridge University Press, Cambridge, United Kingdom, pp. 147-177.
[33] Cusumano A., Peri E., Colazza S. (2016). Interspecific competition/facilitation among insect parasitoids. Current opinion in insect science 14 (April), 12-16, DOI: 10.1016/j.cois.2015.11.006.

[34] Wang X.G., Serrato M.A., Son Y. et al. (2018) Thermal performance of two indigenous pupal parasitoids attacking the invasive Drosophila suzukii (Diptera: Drosophilidae). Environmental Entomology 47 (3), 764-772, DOI: 10.1093/ee/nvy053.

[35] López M., Aluja M., Sivinski J. (1999). Hymenopterous larval-pupal and pupal parasitoids of Anastrepha flies (Diptera: Tephritidae) in Mexico. Biological Control 15 (2), 119-129, DOI: 10.1006/bcon.1999.0711. 

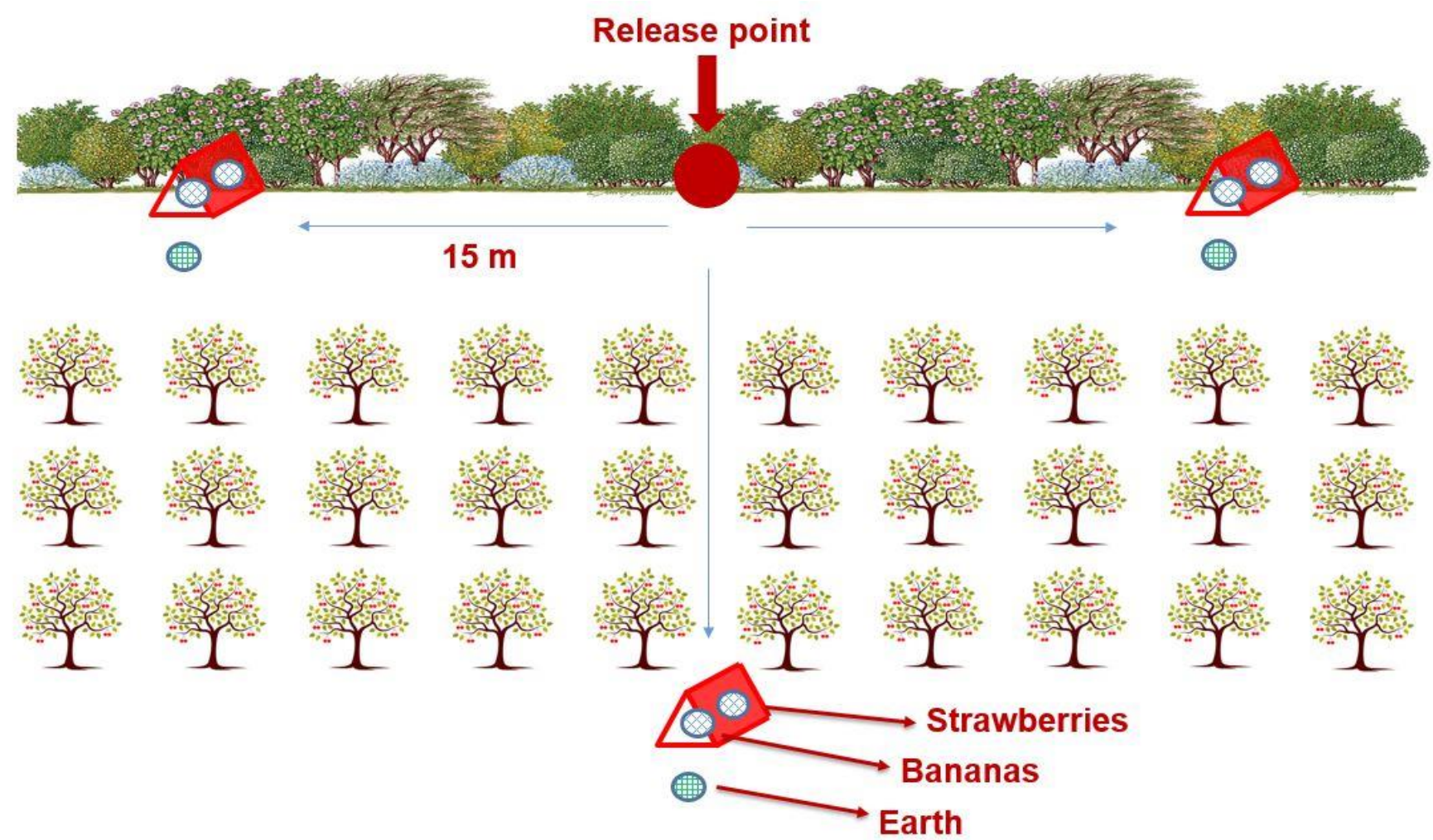

Fig. 1: Scheme of the experimental design of the release trial. 

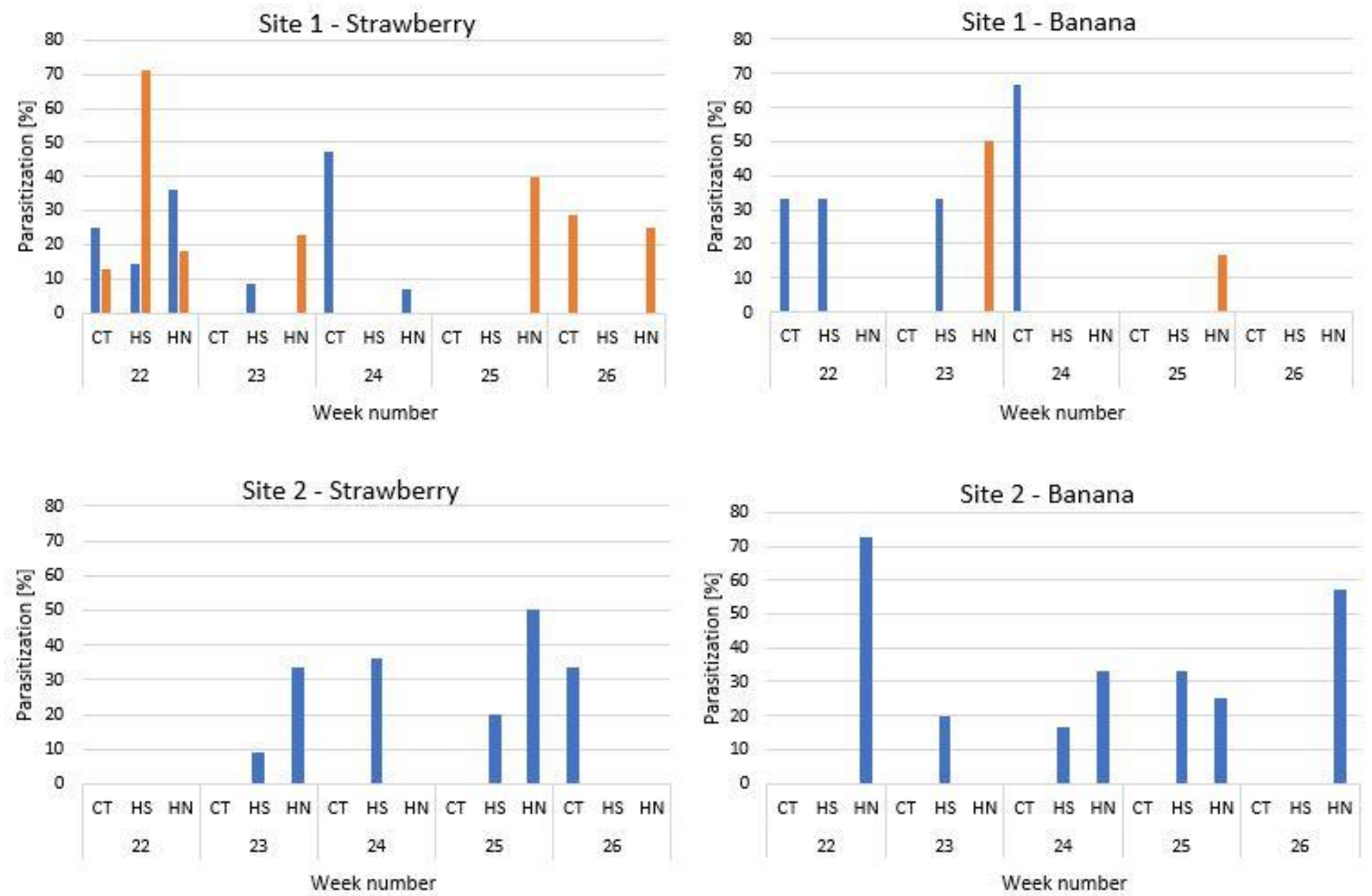

ET. drosophilae a . vindemmiae

Fig. 2: Weekly parasitization of $D$. suzukii pupae in sites 1 and 2 on strawberry and banana. Trap position is indicated by the following abbreviations: cherry tree branch (CT), southern side of the hedgerow (HS) and northern side of the hedgerow (HN). 


\section{APPENDIX 2: TABLES}

Tab. 1: Description of the study sites.

\begin{tabular}{lcc|c}
\multicolumn{1}{c|}{ Locality } & Site & Coordinates & Surrounding environment \\
\hline Laimburg $(220 \mathrm{~m})$ & 1 & $46.3798 \mathrm{~N}, 11.2863 \mathrm{E}$ & Apple orchards, buildings and woodland \\
\hline Lengstein $(915 \mathrm{~m})$ & 2 & $46.5518 \mathrm{~N}, 11.4967 \mathrm{E}$ & Woodland, pond and meadows \\
\hline Kastelruth $(1115 \mathrm{~m})$ & 3 & $46.5586 \mathrm{~N}, 11.5584 \mathrm{E}$ & Apple orchards, meadows and buildings
\end{tabular}

Tab. 2: Temperature in the three sites during the release trial.

$\begin{array}{rrcc} & \text { Mean Temperature Range }\left({ }^{\circ} \mathrm{C}\right) & \text { Maximum temperature }\left({ }^{\circ} \mathrm{C}\right) & \text { Minimum temperature }\left({ }^{\circ} \mathrm{C}\right) \\ \text { Site } 1 & 18.5-25.9 & 35.5 & 9.4 \\ \text { Site 2 } & 14.4-21.5 & 30.5 & 8 \\ \text { Site 3 } & 13.1-20.9 & 28.5 & 8\end{array}$

Tab. 3: Natural presence of parasitoids in the three sites.

\begin{tabular}{|c|c|c|c|}
\hline Date & Site & Nr. parasitized pupae/total pupae found in the trap & Parasitoid species \\
\hline 9 - 16 April & 1 & $0 / 16$ & \\
\hline 16 - 24 April & 1 & $0 / 17$ & \\
\hline \multirow{2}{*}{24 April - 2 May } & 1 & $6 / 20$ & Pachycrepoideus vindemmiae \\
\hline & 2 & $0 / 11$ & \\
\hline \multirow{2}{*}{2 - 9 May } & 1 & $0 / 4$ & \\
\hline & 2 & $0 / 20$ & \\
\hline \multirow{3}{*}{9 - 16 May } & 1 & $5 / 19$ & Leptopilina sp. \\
\hline & 2 & $0 / 7$ & \\
\hline & 3 & $0 / 6$ & \\
\hline \multirow{3}{*}{16 - 23 May } & 1 & $0 / 14$ & \\
\hline & 2 & $0 / 9$ & \\
\hline & 3 & $0 / 7$ & \\
\hline
\end{tabular}


Tab. 4: Mean parasitization (\%) in cups baited with strawberry and banana during the release trial (weeks 22-26) and after the trial (weeks 27-29). Overall parasitization refers to the emerged parasitoids $T$. drosophilae, $P$. vindemmiae and Leptopilina sp.

\begin{tabular}{|c|c|c|c|}
\hline Site & Type of parasitization & $\begin{array}{l}\text { Mean parasitization (\%) } \\
\text { during weeks 22-26 }\end{array}$ & $\begin{array}{c}\text { Mean parasitization (\%) } \\
\text { during weeks } 27-29\end{array}$ \\
\hline \multirow[t]{2}{*}{1} & T. drosophilae & 10.16 & 0 \\
\hline & Overall & 20.2 & 5.69 \\
\hline \multirow[t]{2}{*}{2} & T. drosophilae & 14.68 & 0 \\
\hline & Overall & 14.68 & 5.05 \\
\hline \multirow[t]{2}{*}{3} & T. drosophilae & 0 & 0 \\
\hline & Overall & 0 & 6.03 \\
\hline
\end{tabular}

Dieses Werk ist lizenziert unter einer Creative Commons Namensnennung-Nicht kommerziell 4.0 International Lizenz. Quest'opera è distribuita con Licenza Creative Commons Attribuzione - Non commerciale 4.0 Internazionale. This work is licensed under a Creative Commons Attribution-NonCommercial 4.0 International License.

SFür alle Abbildungen und Tabellen ohne Nennung des Urhebers gilt: (C) Versuchszentrum Laimburg. Per tutte le immagini e tabelle senza menzione dell'artefice vale: (C) Centro di Sperimentazione Laimburg. For all figures and tables without mention of the originator applies: (C) Laimburg Research Centre. 